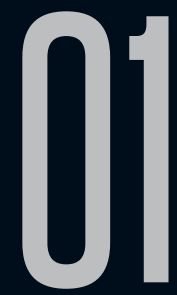

\title{
A INSÓLITA CONSTRUÇÃO DA PERSONAGEM POST-MODERNISTA
}

Ana Paula Arnaut (UC)

Recebido em 28 set 2016. Ana Paula Arnaut - doutorada com agregação pela Aprovado em 25 out 2016.

Universidade de Coimbra, onde leciona Literatura Portuguesa Contemporânea. Publicou, entre outros títulos, Post-Modernismo no Romance Português Contemporâneo: Fios de Ariadne-Máscaras de Proteu (2002); José Saramago (2008), António Lobo Antunes (2009), As mulheres na ficção de António Lobo Antunes. (In)variantes do feminino (2012). Tem também artigos publicados em inúmeras revistas nacionais e internacionais. Colabora no projeto de investigação Figuras da Ficção, coordenado por Carlos Reis, e no Observatório da literatura hipercontemporânea em língua portuguesa, que reúne investigadores de várias Universidades francesas, brasileiras e portuguesas. Contato: arnaut@ci.uc.pt

Resumo: O paradigma post-modernista traduz-se em relações simultâneas de oposição e de permanência de características já existentes em passados mais ou menos próximos ou mais ou menos remotos. Por isso, num efeito semelhante a uma manta de retalhos, a máxima non nova, sed nove (não uma coisa nova, mas de uma nova maneira), constitui a melhor forma de, em termos englobantes, ilustrar a sensibilidade que, desde finais da década de sessenta, tem vindo a marcar o panorama literário em Portugal. Em termos 
mais particulares, como tentaremos provar, mas não esquecendo, no caso do português, a importância da influência modernista no ecletismo da estética em apreço, esta fórmula revela-se também passível de aplicação (e de ilustração, portanto) ao modo como se constrói uma das mais importantes categorias da narrativa - a personagem.

Palavras-chave: Post-Modernismo; Personagem; Tradição; Subversão

Abstract: The post-modernist paradigm reflects, in concurrent relationships of opposition and permanence, some of the existing features of previous literary periods. Thus, in an effect similar to a patchwork, the maxim non nova, sed nove (not a new thing, but in a new way), is, in large part, the best way to illustrate the sensitivity that, since the end of the $60 \mathrm{~s}$, has come to mark the literary landscape in Portugal. More specifically, we will attempt to prove that this formula is applicable to the ways to the way the authors build one of the most important categories of narrative - character. In this endeavor, it is necessary to remember the importance of the modernist influence on the aesthetics of PostModernism, in the Portuguese case

Key-words: Post-Modernism; Character; Tradition; Subversion

Comecei a acreditar que um dos mais complexos problemas da humanidade nos dias que correm, é a entropia comunicativa.

A maka da literatura, porém, é que, frequentemente, as personagens se rebelam contra os seus próprios criadores, recusando-se a agir tal como pré-determinado ou furtandose mesmo ao fim que anteriormente Ihes foi reservado. 
São os leitores livres, portanto, se considerarem isso fulcral para uma narrativa pós-moderna que

se preze, de the desenhar o perfil sociológico, poupando o autor de explicações óbvias. Não é preciso ler Bakhtin para saber que não é apenas o peixe que morre pela boca.

João Melo, O dia em que o Pato Donald comeu pela primeira vez a Margarida

Sem pretendermos nos alargar em considerações teóricas sobre a complexidade semântica do termo e do conceito PostModernismo, não podemos, contudo, deixar de registar que a falta de consenso em torno do seu uso se situa, em primeiro lugar, no estabelecimento de fronteiras relativas às áreas a que se reporta. Daí a utilização quase sempre sinonímica dos termos Post-Modernismo e Post-Modernidade, independentemente da referência à Literatura ou a uma determinada época histórica e social. Em segundo lugar, a dificuldade reside na delimitação a quo de ambos os períodos. Em terceiro lugar, e intrinsecamente ligado ao ponto anterior, põe-se a questão das relações estabelecidas com o passado: Continuidade? Ruptura? Continuidade e ruptura?

Finalmente, entenda-se o advérbio de forma retórica, encontra-se a indagação simultânea sobre a bondade e a validade da instauração do(s) novo(s) paradigma(s), cuja designação, para alguns, não é mais do que "um hífen cercado por uma contradição" (NEWMAN, 1985, p.17), ou uma espécie de unicórnio do século: uma criatura de que todos falam, mas "nunca chegou a ser muito vista pelos deleitosos bosques [literários] portugueses" (Matthias Politycki, Apud BARRENTO, 1990, p.31). 
Seja como for, aceito por muitos, repudiado, talvez, por um número consideravelmente maior de escritores e ensaístas, o Post-Modernismo, e, por extensão, a Post-Modernidade, é, como afirma Fredric Jameson, um termo que não podemos deixar de usar (1991, p.xxii).

Relativamente à primeira questão, na linha de orientação de Thomas Docherty (1983, p.3), de Matei Calinescu (1987, p.268269), ou mais estritamente na de Richard Palmer (1977, p.363364), e contrariamente à posição defendida por Fernando Pinto do Amaral (1991, p.24), propomos que o termo post-modernidade se reporte a um contexto social abrangente, ao que podemos designar por macroparadigma sócio-político-cultural, em que se encontra inserido o Post-Modernismo, entendido como microparadigma estético-literário. Assim, no que toca à post-modernidade em Portugal, cumpre referir que, de acordo com proposta de Boaventura de Sousa Santos, o seu início remonta à não distante década de noventa do século $X X^{1}$.

Aceitando embora a validade da proposta, julgamos, no entanto, ser viável delimitar o início da nova época em meados da década de setenta, depois da Revolução de Abril, génese de radicais mudanças políticas, económicas, sociais e intelectuais² ${ }^{2}$ Reportamo-

1 Boaventura de Sousa Santos subdivide o vasto lapso de tempo compreendido entre 1500 e 1990) em fases que incluem a formação da modernidade (séculos XVI-XVIII) e o teste do seu cumprimento, coincidindo este com a emergência do capitalismo cujo desenvolvimento se apresenta, por seu turno, de modo tripartido: século XIX o capitalismo liberal, final de XIX a fim de 1960 o capitalismo organizado, fim de 1960 até à data de publicação do estudo, o capitalismo financeiro ou desorganizado (1994, p.72-73; cf., também, 74-82). Gianni Vattimo, apesar de considerar que ' $\mathrm{O}$ "pós» de pós-modernidade indica de facto uma despedida da modernidade', refere 'uma dificuldade real: a de isolar uma característica de autêntica viragem nas condições - da existência do pensamento - que se consideram pós-modernas em relação aos traços gerais da modernidade' (1987, p.8-9).

2 Visão menos optimista é a de Vítor Manuel de Aguiar e Silva, para quem, 'em sociedades como a portuguesa, nas quais o projecto da modernidade iluminista representa um projecto relativamente abortado, ou pelo menos em atraso, pretender aplicar este 
nos, como é evidente, ao cenário português, já que no panorama norte-americano, e apesar da prolixidade de conceptualizações glosadas à volta do(s) termo(s) e do(s) conceito(s) em apreço, a mudança de paradigma no Post-II Grande Guerra parece ser um aspecto relativamente consensual.

Acrescente-se, todavia, que talvez seja possível, ainda que de forma muito embrionária, recuar até ao ano de 1968 para começar a entrever a viragem radical que no Portugal de 1974 se consolida. Tal justifica-se em virtude de ser essa a data em que um 'novo estilo' é inaugurado por Marcelo Caetano, um 'salazar' de tonalidades um pouco menos obscuras e escusas que o anterior (SOARES, 1990, p.157, passim).

A proposta de Adolfo Casais Monteiro, que em meados da década de cinquenta faz coincidir o fim da modernidade com a descoberta da bomba atómica, parece-nos, pois, demasiadamente remota para se aplicar ao cenário social português e, consequentemente, e não obstante as repercussões à escala mundial advenientes de tal descoberta, mais próxima de uma delimitação cronológica aplicável a outros cenários sociais:

A modernidade tornou-se um mito como outro qualquer. A modernidade já acabou. Já não é «O grande Pã é morto» que se ouve no fundo das florestas. Agora, por entre o rumor dos arranhacéus, ouve-se: "A modernidade é morta». Precisase de um nome, porque outra coisa nasceu. Se não nasceu, precisa de nascer, porque o homem da modernidade morreu, e enquanto a nova idade não tiver nome, como será possível ela nascer? A modernidade morreu com a descoberta da bomba 
atómica. A modernidade não é suficientemente apocalíptica, nela não cabe a força, a persistência necessária para fazer o homem mais forte do que a bomba atómica. Morreu de medo. (1972, p.19-20)

No que respeita à Literatura Portuguesa, é hoje relativamente consensual que o início do Post-Modernismo deve ter como ponto de referência a publicação de $O$ delfim, de José Cardoso Pires, em 1968. Com efeito, são nas páginas deste romance que confluem, ainda que por vezes em embrião, as principais marcas estéticas, e também ideológicas, do que, na esteira do movimento originário dos Estados Unidos, se consubstancia como uma diferente maneira de fazer e de entender a arte literária.

Da nova literatura sobressaem os seguintes aspectos: a mistura de géneros e a decorrente fluidez genológica, num culto ostensivo e quase sempre subversivo; a insistente e crescente polifonia, em algumas situações a tocar as fronteiras do indecidível, da fragmentação e da (aparente) perda de narratividade; os exercícios metaficcionais, já presentes em romances cómicos e satíricos do século XVIII, mas agora renovados em grau e qualidade e alargados da escrita da história à (re)escrita da História. Sublinhe-se, a propósito do modo como se processa a recuperação do passado, a imposição da paródia como elemento de fundamental importância para a deslegitimação das grandes narrativas que, num entendimento que nos parece pertinente, estendemos a códigos genológicos e periodológicos e, por que, não para o que agora nos interessa, e como verificaremos, ao cânone, ou, se não quisermos ser tão impositivos, à tradição relativa à construção da personagem ${ }^{3}$.

3 As estratégias de construção da personagem post-modernista continuarão (com as inevitáveis oscilações) a ser praticadas no que poderá vir a designar-se literatura hipercontemporânea (tendo como ponto de referência o ano 2000). O conceito que se 
À semelhança do que sucedeu na constituição de períodos literários anteriores, também neste caso a implementação da novidade se traduz, de modo inevitável, em diferentes práticas de escrita, de acordo com o estilo e com as intenções de cada autor, tornando-se válido e aceitável pluralizar o termo e o conceito em apreço: Post-Modernismos e não somente Post-Modernismo. Mas, como acima indiciámos, a implementação do novo traduz-se, ainda, em relações simultâneas de oposição e de permanência de características já existentes em passados mais ou menos próximos ou mais ou menos remotos. Por isso, num efeito semelhante a uma manta de retalhos, parece-nos que a máxima non nova, sed nove (não uma coisa nova, mas de uma nova maneira), constitui a melhor forma de, em termos englobantes, ilustrar a sensibilidade que se tem vindo a impor no panorama literário português. Como escreveu Jean Perreault, "Postmodernism is not a particular style but a cluster of attempts to go beyond modernism. In some cases this means a 'revival' of art styles 'wiped out' by modernism. In others it means anti-object art or what have you" (Apud BERTENS, 1986, p.25)4.

Em termos mais particulares, como tentaremos provar, mas não esquecendo, no caso do português, a importância da influência modernista no ecletismo da estética em apreço, esta fórmula

propõe, não esquecendo que se coloca em relevo um sufixo de graduação aumentativa, parece-nos resultar tanto do culto mais sistemático da variante celebratória do PostModernismo, quanto de uma necessidade de mudança terminológica, correspondente à própria evolução da dinâmica histórica e social, e, por conseguinte, ao imperativo de inscrever novos temas e novos cenários que espelhem as inflexões comportamentais, (inter)individuais e (inter)sociais, decorrentes de um novo mundo, globalizado e em constante transformação. A hipótese de delimitação periodológica está a ser investigada pelo Observatório da literatura hipercontemporânea em língua portuguesa, que reúne investigadores de várias Universidades francesas, brasileiras e portuguesas.

4 A propósito do que acabamos de expor, ver ARNAUT, 2002 e ARNAUT, 2010, de onde retiramos, com variantes, as considerações acima registadas. 
revela-se passível de aplicação (e de ilustração, portanto) ao modo como se constrói uma das mais importantes categorias da narrativa - a personagem. Como escreveu Aguiar e Silva,

A personagem constitui um elemento estrutural indispensável na narrativa romanesca. Sem personagem, ou pelo menos sem agente [...], não existe verdadeiramente narrativa, pois a função e o significado das acções ocorrentes numa sintagmática narrativa dependem primordialmente da atribuição ou da referência dessas acções a uma personagem ou a um agente. (1988, p.687)

De acordo com o uso tradicional, a personagem era (deveria ser) composta (física, psicológica e socialmente) de acordo com processos de caracterização direta (auto e heterocaracterização) e indireta (inferida pelo leitor). Convocando a autorizada voz de Mário de Carvalho, que no seu recente livro Quem disser o contrário é porque tem razão (2014) desvenda o(s) bastidor(es) da escrita ficcional, para, segundo as normas, "dar uma personagem", "instalá-la", "traçar-lhe o arco" (2014, p.162), é necessário, em primeiro lugar, atribuir-lhe um nome, sendo que "A regra é a de que não se devem usar personagens com nome começado pela mesma letra" (2014, p.163). "A seguir à nomeação”, continua o autor,

no «perfil da personagem» enumeram-se, habitualmente, os aspectos físicos (descrição); a gestualidade (brusca, suave, lenta, desenvolta, acanhada); os traços de aparência (vestuário, penteado); os sociais (classe social, família, relações de trabalho, círculo de amigos, hábitos); os psicológicos (terno, bondoso, pérfido, etc., etc.); a história ou background (infância e por aí fora, até 
ao início da acção) e mesmo particularidades como tiques [...]; peculiaridades de ornamentação [...]; tatuagens [...]; ou jeitos (esfregar obsessivamente as mãos, por exemplo). [...].

Pessoas que são mais experimentadas na didáctica da escrita que na escrita propriamente dita recomendarão que, à partida, se conheça e se enumere tudo sobre a personagem, e incitam à construção de um pormenorizado inventário. 0 passado, os jogos de infância, o ambiente familiar, tudo é trazido à colação [...]. (2014, p.164)

A ilustração do que "habitualmente" se faz, ou, talvez, a ilustração do que o leitor formatado pelo cânone do romance tradicional espera, pode, ainda segundo Mário de Carvalho, ser efetuada a partir de algumas personagens de Eça de Queirós - Juliana, de $O$ primo Basílio, por exemplo (e também de Maria Eduarda, de Os Maias, podemos acrescentar) -, ou, de modo talvez mais intenso, a partir de João José Dias (do romance $O$ que fazem as mulheres, de Camilo Castelo Branco) e das duas páginas e meia de pormenores, sarcásticos ou não, não importa, que lhe traçam "arco" (2014, p.154) e que, naturalmente, não excluem a apresentação de outros detalhes sobre a personagem, com ou sem a alternância de pontos de vista.

A propósito do que se diz, não parece difícil identificar, para já, a dimensão subversiva patente em alguns dos romances de autores como José Saramago ou António Lobo Antunes (o primeiro, pertencente ao que podemos classificar como Post-Modernismo moderado, e o segundo como representante de Post-Modernismo celebratório).

Seguindo uma estratégia parcial e embrionariamente anunciada em Manual de pintura e caligrafia (1977), em que os protagonistas 
são identificados pelas iniciais H. e M., romances como Ensaio sobre a cegueira (1995), Ensaio sobre a lucidez (2004), ou Todos os nomes (1997) (em que apenas uma personagem cumpre o critério onomástico), são percorridos por personagens não nomeadas por um nome próprio, sendo este substituído por atributos identificativos, como é possível verificar no romance de 1995, por exemplo: a mulher do médico, o homem da venda preta, o rapazinho estrábico, a rapariga dos óculos escuros, entre outros. No caso de Memorial do convento (1982), sendo embora verdade que as personagens são nomeadas, quebra-se o que se supõe como regra básica de não "usar personagens com nome começado pela mesma letra". Lembre-se, a propósito, a santíssima trindade (terrestre, não celeste) constituída por Bartolomeu, Baltasar e Blimunda 5 .

A título parentético, mas de não pouca importância e interesse, mencionem-se, ainda, os casos dos recentes Livro sem ninguém (2014), de Pedro Guilherme-Moreira, e Gnaisse (2015), de Luís Carmelo. No primeiro, subsiste a subversão levada a cabo pela inexistência de nomes próprios porque, conforme indicado pelo título, a narrativa assume-se 'sem ninguém', isto é, sem personagens-pessoas. Porém, tal como sucede com Raimundo Silva de História do cerco de Lisboa (1989), que, ao escrever a sua versão da conquista da cidade aos mouros, verifica a impossibilidade de negar totalmente os factos históricos oficiais e canonicamente transmitidos, também Pedro Guilherme-Moreira, ou o narrador em sua substituição, acaba por manter "mesma música baixando

5 Julgamos ser também possível considerar que a transgressão a esta 'regra básica' se verifica no facto de, em Levantado do Chão (1980), o nome dos latifundiários apresentar o mesmo segundo elemento: -berto (Norberto, Alberto, Dagoberto, Sigisberto, Adalberto, Ansberto, Gilberto, Contraberto, Angilberto, Floriberto, ou, apenas, Berto). 
de meio-tom todas as notas" (SARAMAGO, 1989, p.254): não há, de facto ninguém, mas as coisas, os objetos e os espaços, tomam o lugar de personagens, tornam-se os "agentes" de que fala Aguiar e Silva, a eles se substituindo na construção dos enredos. Quando ao segundo título, Gnaisse, e sem pretendermos desvendar muito deste tão estranho quanto brilhante livro, convocamo-lo não só porque mantém a não nomeação, na primeira parte, como, além disso, o protagonista (o professor) assume a incapacidade para proceder à caracterização, física (e de modo claro), pelo menos, da protagonista (a aluna): "Porventura o mais curioso é que nunca fui capaz de a descrever fisicamente" (CARMELO, 2015, p.10).

Quanto a António Lobo Antunes, e ainda no que toca à questão do nome, podemos destacar Eu hei-de amar uma pedra (2004), com o Pimpolho, a senhora do medalhão (ou do crochet), entre outros, ou o mais recente Da natureza dos deuses (2015), em que as personagens Raquel, Fátima ou Marçal coexistem com uma série de outras nunca referidas pelo seu nome próprio: a senhora, o senhor doutor, o adjunto, a secretária do adjunto, a rapariga loira, a criatura de vermelho, etc.

Além disso, o que sobressai é o facto de o 'arco' que se traça das personagens passar a ser conseguido, essencialmente, a partir de referências não tão extensas e pormenorizadas. Com efeito, as informações conducentes à caracterização dos seres que povoam as narrativas são, agora, disseminadas, se não estilhaçadas, ao longo da narrativa, numa prática que, exigindo uma participação mais ativa do leitor, seguramente desestabiliza a sua relação com o mundo da ficção, levando-o, não a voluntariamente suspender a descrença no que lhe é dado a ler, 
mas, antes, a voluntariamente suspender a crença na realidade dos universos apresentados.

Por outras palavras, se uma prática tradicional de composição da personagem implica que ela surja praticamente acabada, completa, através de listas mais ou menos longas de atributos que fazem corresponder o real do texto ao real do mundo extratextual, no caso do romance post-modernista o leitor deve vestir a pele de um detetive para tentar fazer sentido dos fragmentos que the vão sendo apresentados. Estes, dependendo dos autores, podem surgir mais ou menos fundidos e confundidos, de acordo com o nível de entropia causado não só por diversos graus de ausência de narratividade, mas principalmente, pelo recurso a estratégias de polifonia (e a outras, como diferentes tipos de letra - caso de Lobo Antunes -, ou uso peculiar da pontuação - caso também de José Saramago) que, tantas vezes, impedem o leitor de estabelecer correspondências absolutamente certas e exatas entre o que se diz (direta ou indiretamente) e sobre quem se diz.

Acresce que, no caso de António Lobo Antunes, a impressão, a certeza, sobre a disseminação da e na caracterização das personagens decorre do facto de, com muita frequência, esta resultar de um processo que julgamos poder classificar como em segunda mão, isto é, do paralelismo que se torna necessário estabelecer entre a personagem (personalidade, vivência, físico) e representações (pictóricas e escultóricas) de diversas figuras (religiosas ou não).

Assim, as almas quebradas, as vidas tortas e agónicas, as dores causadas por violências de índole diversa, e também os medos e os dilaceramentos interiores, não são facultados de 
modo preciso e inequívoco, antes devendo ser adivinhados, ou, melhor, descodificados, a partir de uma técnica de transferência das imagens/figuras/ícones para as personagens: "um Cristo (...) torto na parede", como réplica dos sentimentos do autista, de $O$ arquipélago da insónia (ANTUNES, 2008, p.17); uma "Nossa Senhora numa nuvenzinha de barro com um ângulo quebrado", similar à incompletude sentida por Fátima de Exortação aos Crocodilos (ANTUNES, 1999, p.201); uma boneca "com o verniz das bochechas a estalar", "uma Branca de Neve, a que faltavam dois anões", "um leão de veludo só com três patas", correspondentes à fragmentação interior de algumas das personagens de Da natureza dos deuses (ANTUNES, 2015, p.16,145,212, respetivamente); um outro Cristo que, em Comissão das Lágrimas, agoniza "na parede, tentando agarrar os pregos das mãos com os dedos curvados", torna-se ilustrativo do desespero dos prisioneiros que são torturados na Cadeia de São Paulo (ANTUNES, 2011, p.190) ${ }^{6}$.

De acordo com o que acabamos de expor, e numa ilustração retirada do domínio da música, talvez possamos dizer que a personagem passa a ser construída em vibrato, ou em diferentes escalas de vibrato, de acordo com as particularidades técnicas do autor, isto é, não através de uma sonoridade límpida, clara, mas, pelo contrário, através de ondulações e de modulações expressivas, de quase ecos, em certos momentos, do som tornado escrita. Numa outra dimensão, igualmente ilustrativa do efeito de caracterização não linear, isto é, não resultante da apresentação de listas de características mais ou menos exaustivas e, tantas vezes, repetitivas, a imagem que nos vem à mente é a do efeito spin ball, 
do cricket (ou top spin, no caso do ténis), com as consequentes implicações no modo como se recebe a bola. Lembre-se, ainda, de $A$ natureza dos deuses, a flutuante e líquida caracterização das personagens, espalhada pela narrativa de quase seiscentas páginas em ténues e instáveis timbres de voz própria e/ou de vozes alheias; timbres tão ténues e tão instáveis que a figuração física que delas fazemos as transforma em quase fantasmas, de corpo e de rosto indistintos.

Retomado o universo da Literatura, e convocando agora a aliança entre a construção da personagem e o recurso a estratégias metaficcionais de índole diversa, o efeito que assim se obtém é muito semelhante ao da dupla pintura de que nos fala H. em Manual de pintura e caligrafia. Abandonando a representação realista por que era conhecido, o resultado, a diferença do novo quadro do pintor, causa uma impressão de desconforto que levará os retratados, os senhores da Lapa, a recusar a encomenda feita:

A semelhança dos modelos não podia ser posta em dúvida, mas, na verdade, este quadro não era um digno sucessor das escorridas e dessoradas telas à custa das quais eu vinha vivendo. Tanto a mulher como o homem, estavam (como vou dizer?) duplamente pintados, isto é, com as primeiras tintas necessárias para lhes reproduzir os traços e os planos do rosto, da cabeça, do pescoço, e depois, sobre tudo isto, mas de uma maneira que não permitia descobrir facilmente onde estava o excesso, outra pintura se sobrepunha, que, por assim dizer, não fazia mais do que acentuar o que já lá estava. No caso da mulher o efeito era mais visível porque com ela tivera eu de interpor 
a pintura intermédia que era a maquilhagem. 0 quadro produzia uma impressão de desconforto, como a de um riso súbito no interior duma casa deserta. (SARAMAGO, 1985, p.242)

A dupla pintura, ou, se preferirmos, a exposição das costuras da obra, com o consequente desconforto causado pela subversão das expectativas relativamente a uma técnica tradicional, pode ser ilustrada a partir de História do cerco de Lisboa, quando, depois de alertar o leitor para a 'hábil mudança do plano narrativo' (SARAMAGO, 1989, p.120-121), o narrador chama a atenção para a tentativa de "encontrar por aqui [arraial português] alguém que possa servir de personagem a Raimundo Silva, pois este, tímido por natureza ou feitio, infenso a multidões, deixou-se ficar na sua janela da Rua do Milagre de Santo António" (SARAMAGO, 1989, p.184). Em outras situações, as hipóteses relativas a opções linguísticas são claramente mantidas na tessitura narrativa: "estranho caso, um sinal de inquietação toca algures o corpo de Raimundo Silva, perturbação seria a palavra justa, agora deveríamos escolher o adjectivo adequado para acompanhá-la, por exemplo, sexual, porém não o faremos" (SARAMAGO, 1989, p.87).

Seja como for, a verdade é que a nova arte de fazer a personagem, e, por extensão, o novo entendimento do género romance, se encontram estreitamente relacionados com o mundo que subjaz à sua conceção. E, assim, acompanhando o ritmo cada vez mais frenético dos tempos coevos e as consequentes dispersões vivenciais, numa linha de prolongamento, sublinhe-se, da prática estética do Modernismo, as personagens surgem cada vez mais afastadas de uma conceção positivista, iluminista, isto é, de "um 
indivíduo totalmente centrado, unificado, dotado de capacidades de razão, de consciência e de ação", um indivíduo "cujo "centro» consistia num núcleo interior, que emergia pela primeira vez quando o sujeito nascia e com ele se desenvolvia, ainda que permanecendo essencialmente o mesmo - contínuo ou «idêntico» a ele - ao longo da [sua] existência" (HALL, 1997, p.11).

Pelo contrário, adaptando ao contexto o que António Lobo Antunes escreve sobre um dos seres que transitam em $D a$ natureza dos deuses, o sujeito post-moderno e, por consequência, a personagem post-modernista, parece despenhar-se "no parapeito de si mesm[a]" (2015, p.179), transformando-se numa "celebração móvel" resultado, como já sugerimos, de uma sociedade também ela em crescente grau de desagregação e de transformação. "A identidade plenamente unificada, completa, segura e coerente' passa a ser 'uma fantasia” (HALL, 1997, p.1314) e "Os projectos de vida individuais não encontram nenhum terreno estável em que acomodem uma âncora, e os esforços de constituição da identidade individual não podem retificar as conseqüências do 'desencaixe', deter o eu flutuante e à deriva" (BAUMAN, 1998, p.32). Não por acaso, portanto, ainda na sequência do Modernismo do início do século $X X$, recorram os tópicos do espelho ou da fragmentação do eu, traduzido, este, no caso da constelação ficcional antuniana, na reiteração constante da pergunta sobre quem se é en $^{7}$ numa linha, portanto, ainda obsessivamente presente no romance acima mencionado (ANTUNES, 2015, p.18 passim). Citamos:

7 Ver, a propósito, ARNAUT, 2011, p.392-394. Sobre o tópico do espelho em Da natureza dos deuses, ver, por exemplo, pp.50, 76, 120, 201, 281, 284, 290, 465; sobre quem se é, ver, entre outras, p.18, 27, 143, 312, 324, 337, 457. 
À noite, quando não sou capaz de dormir, e há tantas noites em que não sou capaz de dormir, ando pela casa de pijama, descalço, sem acender a luz, no meio de sombras, corredores, móveis, escadas, sentindo o mármore nos pés, querendo fazer parte de $\mathrm{mim}$, e a pensar

- Não é aqui que eu moro

cercado de ecos sem vozes e brilhos parecidos com soslaios cujos olhos não conheço, a quem pertencerão, onde é que os foram buscar, ando pela casa sem ver a janela lá em cima nem a secretária do meu adjunto a passar por mim já não zangada, cúmplice

- Não lhe apetece mais senhor doutor?

sinto as rosas de cheiro, sinto o vento nas dunas, se me encontrasse levava-me, não mencionando os estalos dos pinheiros e os cotovelos do mar que os empurram, em pequeno ficava na cama, igual a uma sementinha na terra, agora tento encontrar quem fui e não acho [...]. (ANTUNES, 2015, p.361 - grifo nosso)

Neste outro exemplo, torna-se muito claro não só a incapacidade para criar âncoras, simbolizada no estranho e indecifrável(?) sem abrigo que percorre toda a narrativa, mas também o papel de primordial importância que a nós, leitores, cabe na (tentativa) de fazer sentido de um mundo vagamente apresentado e das suas personagens não menos vagamente construídas:

[mãe da senhora] o sem abrigo a contornar a estufa continuando sempre, nunca o vi parado, resoluto, com pressa, quem de nós tem nome neste livro, quem existe de facto, quem sou eu realmente, ou o meu marido, ou vocês que lêem, será que o livro, agora a sério, existe, com as bolas e as pancadas 
nas bolas o som das palavras inaudível, não é, ou desarrumadas como as figueiras bravas e as dunas, os pingos da concha de Vénus tombando um a um no meio das páginas dispersando as sílabas, a sombra rápida do voo dos pássaros escurecendo os parágrafos conforme escurecem as vossas caras e a minha, o meu marido desligava a luz antes de se deitar ou ao deitar-se, tanto faz, de modo que para continuarem comigo têm de acender uma lâmpada vossa, se não a tiverem talvez consigam percebê-lo ao meu lado por um suspiro de molas e uma vibração do corpo. (ANTUNES, 2015, p.312 - grifo nosso)

A incapacidade, se não a impossibilidade, de saber quem se é (ou quem se foi), em estreita ligação com a dimensão fragmentária da personagem ${ }^{8}$, encontra ainda tradução formal, neste como em outros romances, na manutenção de diversas estratégias de suspensão da ideia, ou da palavra ${ }^{9}$, que pode ou não ser posteriormente completada:

se bem que nesse caso Amélia a telefonista do armazém onde trabalhava, agora César, que se soubesse, nenhum, um companheiro da es, as marcas a cal do ténis apa, cola, um colega da, gadas, as cadeiras dos palhaços com, da tropa, com folhas secas já duras, até este escritório um abandono de cave mas não se acabou ainda, não acabei ainda, tenho receio que, quando os gansos bravos voltarem a passar, o sem abrigo parta com

8 Por exemplo: [Fátima] "eu até então sem importância para ninguém incluindo o meu filho de gatas com o seu brinquedo a que faltava uma roda, nunca houve nada inteiro perto de mim, o meu pai, virados os quarenta, quase nenhum dente nas gengivas, alheado, o meu filho herdou o egoísmo sei muito bem de que parte, oxalá não tenha herdado os maus hábitos", [Cantora] "uma janela ao fundo com três ou quatro pessoas, entre elas a médica gorda, com um vestido horrível, debruçadas a estudarem fragmentos de mim, apontando fosse o que fosse com um lápis". (ANTUNES, 2015, p.20 e 531, respetivamente)

9 Sobre o assunto, ver ARNAUT, 2009, p.41-45. 
eles e o sujeito que nos escreve desista do livro [...]. (ANTUNES, 2015, p.380 - grifos nossos)

Aliada às estratégias de composição da personagem que acabamos de referir, uma outra deve ser considerada, ainda que, naturalmente, nessa linha de continuidade descontínua traduzida pela máxima non nova sed nove, que já propusemos caracterizar a prática do Post-Modernismo. Referimo-nos ao facto de, num uso que vemos como crescente, a personagem passar a ser o resultado de processos de figuração mais complexos e, por isso, mais interessantes. Deste modo, como já propusemos em outra ocasião ${ }^{10}$ fazendo apelo às competências culturais de quem lê (ou, se quisermos, aos modelos mentais do leitor ${ }^{11}$ ) e exigindo, por isso, uma participação mais ativa, ou, melhor, ainda mais ativa, na decifração progressiva ${ }^{12}$ do retrato ('como modelação discursiva e descritiva ${ }^{13}$ ), a estratégia que é posta em jogo é a intertextualidade (por vezes, uma intertextualidade desviada, ou uma intertextualidade de sentido(s) alargado(s), abrindo-se a uma dinâmica de relação não apenas entre textos, mas entre o texto e o

10 Arnaut, no prelo.

11 Uri Margolin (2005, p.52) propõe dois modelos teóricos de construção da personagem, o mimético ou representacional ('treating character as a human or human like being') o não mimético ('reducing it to a text-grammatical, lexical, or composicional unit'), distinguindo, no primeiro, três paradigmas, diversos mas, naturalmente, complementares: o semântico ('possible world theories'), o cognitivo ('readers' mental models') e o comunicativo ('the processo of narrative mediation').

12 Segundo Philippe Hamon (1977, p.126), a 'etiqueta semântica' da personagem 'n'est pas une 'donnée' a priori, et stable, qu'il s'agirait purement de reconnaitre, mais une construction qui s'effetue progressivement, le temps d'une lecture, le temps d'une aventure fictive'. Ver também Garrido Dominguez, 1996: 90. Sobre o papel fundamental do leitor na (re)construção das personagens a partir de dados extra e intertextuais, ver Jouve, 2008, p.29.

13 Além desta funcionalidade, Carlos Reis (2013a) atribui ao retrato uma outra, vendo-o "como objeto ficcional, pintado, desenhado ou fotografado e presente numa ação narrativa antes de mais como elemento decorativo". 
real a que se reporta) ${ }^{14}$, como nos parece suceder com a dinâmica relacional estabelecida entre a representação de personagens e a representação de figuras religiosas ou outras a que acima fizemos referência a propósito da constelação ficcional antuniana.

Antes, porém, de avaliarmos o modo como se desenham esses laços intertextuais, cabe lembrar que, segundo Carlos Reis,

O conceito de figuração designa um processo ou um conjunto de processos constitutivos de entidades ficcionais, de natureza e de feição antropomórfica, conduzindo à individualização de personagens em universos que as acolhem $e$ com os quais elas interagem. Tal individualização verifica-se sobretudo em contextos narrativos e em contextos dramáticos, mas acontece, igualmente de modo residual, em contextos de enunciação poética; passa-se isto, em especial, quando estão em causa composições dotadas de um certo índice de narratividade. Ou seja: a personagem pode ser figurada na poesia lírica. Por outro lado, a figuração deve ser encarada em aceção translata, quando observamos a sua ocorrência em discursos que não são formal ou institucionalmente literários. (...)

Assim, sendo um processo ou um conjunto de processos, a figuração é dinâmica, gradual e complexa. Isto significa três coisas: que normalmente ela não se esgota num lugar específico do texto; que ela se vai elaborando e completando ao longo da narrativa; e que, por aquela sua natureza dinâmica, a figuração não se restringe a uma descrição, no sentido técnico e narratológico do termo, nem mesmo a uma caracterização, embora esta possa ser entendida como seu componente importante. $\mathrm{O}$ que me leva a realçar o

14 Para Laurent Jenny (1979 [1976], p.21), a intertextualidade dá origem a "um novo modo de leitura que faz estalar a linearidade do texto". 
seguinte: a figuração não é simplesmente um outro modo de entender a convencional caracterização, sendo antes um processo mais amplo, englobante e consequente. (2015, p.121-123)

De acordo com o que lemos, a personagem faz-se, então, através da interação entre vários dispositivos: "retórico-discursivos", "de ficcionalização (ou paraficcionais)" (REIS, 2015, p.123), em que nos parece fazer sentido inserir a questão da intertextualidade, em conjunto também com o ponto de vista do narrador, e "de conformação acional". Se os primeiros nos parecem passíveis de identificação com as tradicionais técnicas de caracterização, que não deixam de existir no romance post-modernista, embora, como já escrevemos, não nos pareça que a personagem seja sujeita a processos de caracterização tão exaustivos quanto antes, os seguintes consubstanciam uma sistematização de uma nova forma de ler, e, antes, de construir, a personagem romanesca.

A nova forma permitida e ilustrada pela intertextualidade (exata ou de sentido alargado, em que podemos incluir a caracterização em segunda mão que acima mencionámos), agora praticada em grau mais intenso e ostensivo, do que no passado ${ }^{15}$, evita a já referida listagem exaustiva, requerendo, por isso, mais uma vez, a participação ativa do leitor que, com muita frequência, vê posta em causa a sua enciclopédia. Em Astronomia, o mais recente livro

15 Recordem-se, a título de exemplo, a caracterização de Maria Monforte também feita a partir da referência/comparação entre a sua pele e um mármore grego (QUEIRÓS, s./d., p.29) e o contributo facultado pela escolha do nome Judite para a protagonista de Nome de guerra de Almada Negreiros: "Judite é um nome de mulher a quem a Bíblia faz cortar a cabeça de Holofernes. Ambos são verdadeiros e garantidos" (2016 [1938]: 13). A nova dimensão intertextual que se põe em prática pode trazer para o centro da literatura referências que algumas mentalidades conservadoras consideram marginais (ou ex-cêntricas, como escreveu na sua Poética do pós-modernismo (1988, p.65), isto é, menos literárias. 
de Mário Cláudio (2015), as potencialidades do recurso a técnicas intertextuais podem ser verificadas a partir do excerto em que o narrador-autor relembra alguns dos seus professores do liceu:

O rosto do professor Rosa dá agora lugar a cinco outros, o da de Português, uma senhora roliça como a fada madrinha, imaginada por Walt Disney para a Gata Borralheira, o da de Francês, uma megera escanifrada, e inexorável nas notas, que consta carregar no cérebro um tumor colossal, o de Ciências Naturais, um segundo gordo, que passa o tempo a levantar a perna esquerda, no intuito de acamar as bolas confortavelmente, o do de Matemática, uma variante da cobra-cuspideira, que lança em torno de si, e nas lentes dos próprios óculos, um chuvisco cintilante de perdigotos, e o do de Desenho, um cavalheiro melancólico, que assume na fisionomia, e sucessivamente, 0 traçado dos polígonos que exige executados a tinta-da-china. Descontam-se deste elenco três mestres menores, o de Canto Coral, um anão cruzado de marciano, que se resigna ao papel de vítima da crueldade dos pequenos demónios, o de Religião e Moral, um padreco untuoso, que impõe à ganapada absurdos sacrifícios durante a Semana Santa, e o de Ginástica, um médico desacreditado, que obriga os catraios a glaciais duches no pino do Inverno. (p.191 - grifo nosso)

Independentemente do facto de os laços intertextos e intermundos serem mais ou menos explicados (mais para menos do que para mais), sempre se exige a ativação da enciclopédia de quem lê, ficando o verdadeiro retrato sujeito à qualidade e à bondade desta. Por outras palavras, e a título de exemplo, a composição do retrato da professora de Português só fará sentido se soubermos distinguir a fada madrinha idealizada por Walt 
Disney (Figura 1) da concebida, entre outras, para a série Once upon a time, em 2011 (criada por Edward Kitsis e Adam Horowitz, personagem interpretada por Catherine Lough Haggquist) (Figura 2), ou para a versão do filme Cinderela, de 2015 (dirigido por Keneth Branagh, personagem interpretada por Helena Bonham Carter) (Figura 3). Neste caso, as imagens - a (re)construir - valem, francamente, as palavras.

Em outros momentos, e já numa escola diferente, a caracterização de outros educadores é feita apenas a partir de uma inscrição intertextual onomástica, como sucede com os professores "Tournesol16 e Palomar, impagáveis personagens das aventuras de Tintim" (CLÁUDIO, 2015, p.197) (Figura 4).

Para quem conhece o professor Girassol dos livros de Tintim, não parece haver necessidade, na verdade, de qualquer informação adicional, ou das "explicações óbvias" mencionadas por João Melo numa das nossas epígrafes, quer no que respeita ao aspeto físico do docente que se recorda quer, julgamos legítimo considerar, no que concerne à sua dimensão psicológica. Mas, para quem não domina o mundo criado por Hergé, a situação é de índole bem diversa: o trabalho poupado ao autor é trabalho duplamente cobrado ao leitor, sob pena de a incapacidade para descodificar a caracterização levar à "entropia comunicativa". Uma entropia comunicativa que se agrava, no caso de Astronomia, com citações sistemáticas (com remissão para notas finais), nas três partes da narrativa (Nebulosa, Galáxia e Cosmos), de livros do próprio autor ou de outros companheiros de ofício.

16 Trifólio Girassol (Tryphon Tournesol) - cientista cuja quase surdez o leva a agir de forma equivocada e trapalhona nas mais diversas situações. Terá sido inspirado no explorador suíço Auguste Piccard. 
Seja como for, portanto, recuperando parcialmente a exigência patente na citação da mãe da senhora do romance Da natureza dos deuses, parece que, de facto, para compormos o retrato da personagem em contexto post-modernista, para podermos continuar com ela e assim fazer-Ihe e dar-Ihe sentido(s), há, sempre, que "acender uma lâmpada [n]ossa" (ANTUNES, 2015, p.312). Ou talvez várias, dependendo da entropia dos universos oferecidos.

\section{REFERÊNCIAS}

. (2004). Eu hei-de amar uma pedra. Alfragide: Dom Quixote.

- (2008). O arquipélago da insónia. Alfragide: Dom Quixote.

. (2011). Comissão das lágrimas. Alfragide: Dom Quixote.

. (2015). Da natureza dos deuses. Alfragide: Dom Quixote.

ARNAUT, Ana Paula (no prelo). "Intertextualidade e figuração da personagem em As Pessoas Felizes (Agustina Bessa-Luís)". In: Ética e política na obra de Agustina Bessa-Luís.

. (2012). As mulheres na ficção de António Lobo Antunes. (In)variantes do feminino. Alfragide: Texto.

. (2011). "Sôbolos rios que vão de António Lobo Antunes: quando as semelhanças não podem ser coincidências". In: João Amadeu Carvalho da Silva et alii (Orgs.), Pensar a literatura no séc. XXI. Braga: Publicações da Faculdade de Filosofia/Universidade Católica Portuguesa. p.385-394.

. (2010). "Post-Modernismo: o futuro do passado no romance português contemporâneo". In: Via Atlântica. n17. p.129-140. . (2009). António Lobo Antunes. Lisboa: Edições 70.

. (2002). Post-Modernismo no romance português contemporâneo: Fios de Ariadne-máscaras de Proteu. Coimbra: Almedina.

BARRENTO, João (1990). "A razão transversal: requiem pelo pós-moderno". In: Vértice, 25 de abril. p.31-36. 
BAUMAN, Zygmunt (1998). O mal-estar da pós-modernidade. Rio de Janeiro, Jorge Zahar Editor.

BERTENS, Hans (1986). "The Postmodern Weltanschauung and its Relation with Modernism". In: FOKKEMA, Douwe e BERTENS, Hans (Eds.). Approaching Postmodernism. Amsterdam/Philadelphia: John Benjamins.

CALINESCU, Mattei (1987). Five Faces of Modernity. Modernism, Avant-Garde, Decadence, Kitsch, Postmodernism. Durham: Duke University Press.

CARMELO, Luís (2015). Gnaisse. Lisboa: Abysmo.

CARVALHO, Mário de (2014). Quem disser o contrário é porque tem razão. Letras sem tretas. Porto: Porto Editora.

CLÁUDIO, Mário (2015), Astronomia. Alfragide: Dom Quixote.

DOCHERTY, Thomas (1993). Postmodernism: A Reader. New York: Harvester Wheatsheaf.

HALL, Stuart (1997). A Identidade cultural na pós-modernidade. Rio de Janeiro, DP \& A. HAMON, Philippe (1977). "Pour un statut sémiologique du personnage". In: BARTHES, Roland et alii, Poétique du récit. Paris: Seuil. p.115-180.

HUTCHEON, Linda (1988). Poética do pós-modernismo. Rio de Janeiro: Imago. JAMESON, Fredric (1991). Postmodernism or the Cultural Logic of Late Capitalism. London: New York: Verso.

JENNY, Laurent (1979 [1976]). "A estratégia da forma". In: Poétique (Intertextualidades). n27, p.5-49.

JOUVE, Vincent (2008). L'effet-personnage dans le roman. Paris: PUF.

MARGOLIN, Uri (2005). "Character". In: D. Herman [et al.] (eds.), Routledge Encyclopedia of Narrative Theory. London: Routledge.

MELO, João (2006). O dia em que o pato Donald comeu pela primeira vez a Margarida. Lisboa: Caminho.

MONTEIRO, Adolfo Casais (1972). "A ideia de modernidade". In: A palavra essencial. 2.ed. Lisboa: Verbo.

MOREIRA, Pedro Guilherme (2014). Livro sem ninguém. Alfragide: Dom Quixote. NEGREIROS, José de Almada (2016). Nome de guerra. 4.ed. Porto: Assírio \& Alvim. 
NEWMAN, Charles (1985). The Post-Modern Aura. The Act of Fiction in an Age of Inflation. Evanston: Northwestern University Press.

PALMER, Richard E. (1977). "Postmodernity and Hermeneutics". In: Boundary 2. Vol.5, n2, Winter. p.363-388.

REIS, Carlos (2015). Pessoas de livro. Estudos sobre a personagem. Coimbra: Imprensa da Universidade de Coimbra. . (2013). "Figuração, Retrato". In http://wp.me/p2twYC-cw Acesso em 30.Jun.2016.

QUEIRÓS, Eça de (s./d.). Os Maias. 13.ed. Lisboa: Livros do Brasil.

SANTOS, Boaventura de Sousa (1994). Pela mão de Alice. O social e o político na pós-modernidade. Porto: Afrontamento.

SARAMAGO, José (1985). Manual de pintura e caligrafia. 3.ed. Lisboa: Caminho. . (1980). Levantado do chão. Lisboa: Caminho.

. (1982). Memorial do convento. Lisboa: Caminho. . (1989). História do cerco de Lisboa. Lisboa: Caminho. . (1995). Ensaio sobre a cegueira. Lisboa: Caminho.

SILVA, Vítor Manuel de Aguiar e (1988). Teoria da literatura. 8.ed. Coimbra: Almedina.

- (1989). "Vítor Manuel de Aguiar e Silva: Pós-modernismo e pósmodernidade", entrevista conduzida por Américo Lindeza Diogo et alii. In: O Primeiro de Janeiro. Suplemento das artes e das letras, 2 de Agosto.

SOARES, Mário (1990). “Da queda de Salazar (1968) às «Eleições» de 1969”. In: MEDINA, João (dir.), Post-Modernismo no romance português contemporâneo. Fios de Ariadne-máscaras de Proteu. Vol. Estado Novo II. Camarate: Multilar. VATTIMO, Gianni (1987). O fim da modernidade. Niilismo e hermenêutica na cultura pós-moderna. Lisboa: Presença. 


\section{ANEXO}

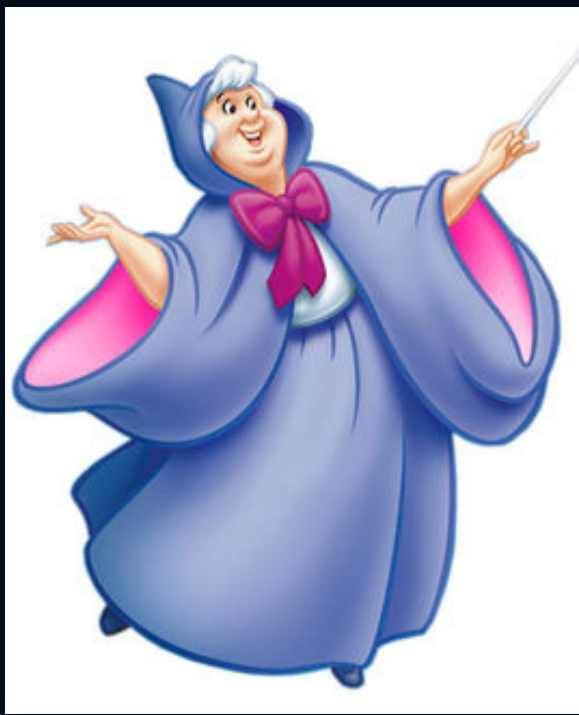

Figura 1 (fada madrinha - Walt Disney)

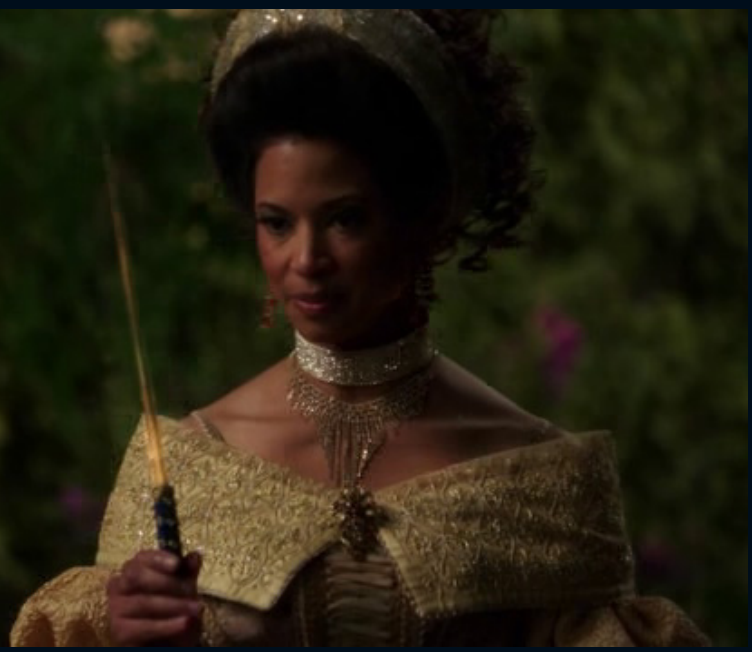

Figura 2 (fada madrinha - série Once upon a time) 


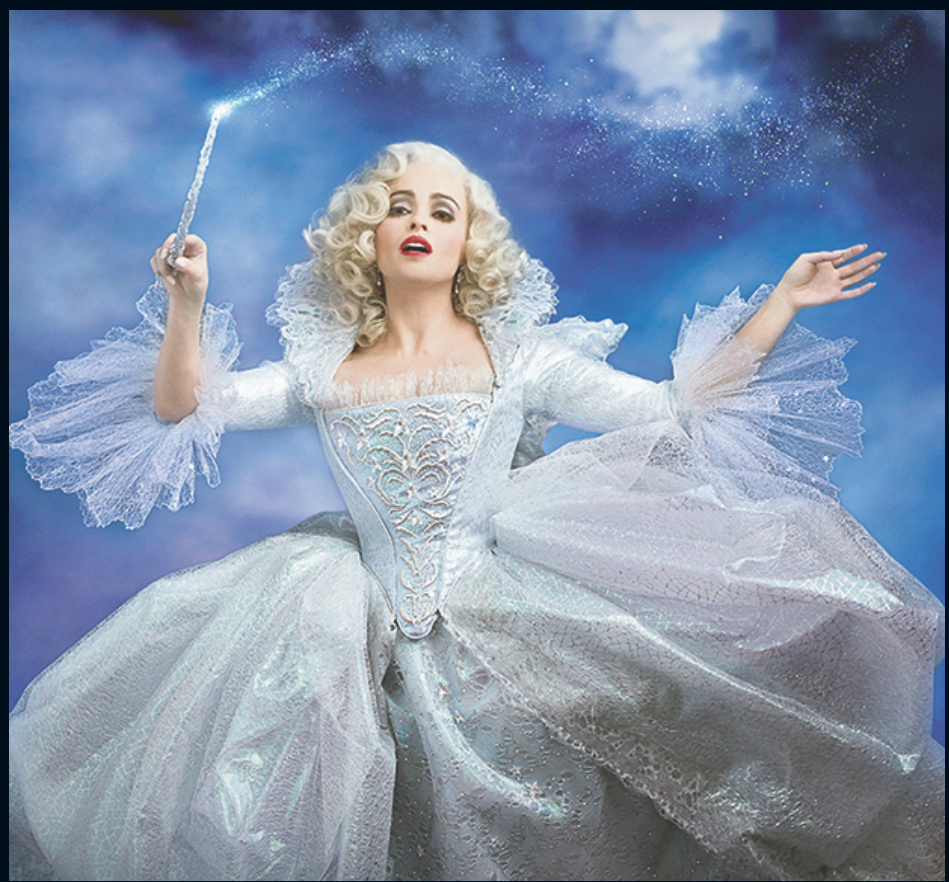

Figura 3 (fada madrinha - filme Cinderela)

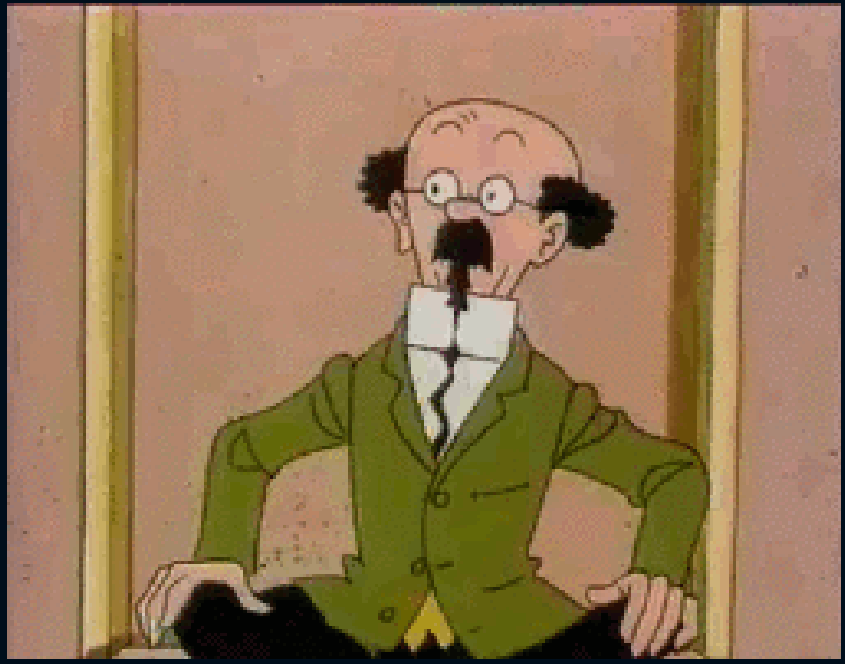

Figura 4 (Professor Tournesol) 